\title{
The Relationship between Visual Satisfaction and Water Clarity and Quality Management in Tourism Fishing Ports
}

\author{
Lee-Hsueh Lee \\ Department of Landscape Architecture, Chung Hua University, Taiwan \\ Email: Islee@chu.edu.tw
}

Received 16 February 2016; accepted 27 June 2016; published 30 June 2016

Copyright (C) 2016 by author and Scientific Research Publishing Inc.

This work is licensed under the Creative Commons Attribution International License (CC BY). http://creativecommons.org/licenses/by/4.0/

(c) (i) Open Access

\section{Abstract}

Visual satisfaction of the tourists with a water body is strongly influenced by water clarity, which is in turn influenced by a number of water quality parameters. Visual satisfaction thus stands to benefit from having a water quality management tool that results in better water clarity. A Clarity Suitability Index of Water Quality (CSIWQ), derived from clarity suitability curves of selected water quality parameters, can allow estimation of optimal values for these parameters, while ensuring high visual satisfaction among tourists. The present study used sampling and survey methodologies to investigate water clarity and quality at five tourism fishing ports; simultaneously, tourists' visual satisfaction with a water body was assessed through a questionnaire based on their perceptions. The relationship between tourists' visual satisfaction and water clarity was found to be positive and strong, with water clarity having predictive power of $74.2 \%$. The study showed that DO, BOD, TP, and SS were the most critical parameters for water clarity. A continued product approach of CSIWQ was found to be most appropriate for describing the relationship between water clarity and these four parameters. This enabled a CSIWQ Index value to be calculated. With a CSIWQ value of 0.6 , water clarity would be more than $2.08 \mathrm{~m}$, and tourists would experience very high satisfaction. CSI curves showed that DO would preferably be $9.0 \mathrm{mg} / \mathrm{L}$, and BOD, TP, and SS less than $0.5 \mathrm{mg} / \mathrm{L}, 0.12 \mathrm{mg} / \mathrm{L}$, and $45.0 \mathrm{mg} / \mathrm{L}$, respectively. The model thus produced valuable insights for assessing and improving water quality and ensuring high levels of visual satisfaction among tourists in tourism fishing ports. This model identified only four parameters but could be improved by ensuring that other water quality parameters were included, to encourage an increase in the number of tourists and to include monitoring of more pollutant sources.

\section{Keywords}

Visual Satisfaction, Suitability Curve, Suitability Index Model, Clarity-Based Water Quality Management 


\section{Introduction}

Water is one of the most indispensable elements in different landscapes; it has a visual reverse value in scenery and provides users with recreational opportunities [1]. Landscapes with large water bodies (i.e., oceans) tend to be among the most preferred landscapes [2], and water bodies are in fact also positive factors in landscape perception [3]-[5]. Water bodies therefore impact upon tourists' preferences, with the tourists having been shown to be willing to incur additional costs to visit landscapes with water bodies [4] [6]. Factors such as water quality, clarity, and color influence viewers' assessments of the amenity or aesthetic value of these water landscapes [7]-[18]. Furthermore, Ryan [18], Pfluger et al. [19], and Vesterinen et al. [20] have shown that water clarity is an important determinant of public perception of water quality. A water surface with a good visual quality can attract more tourists [1] [21] and the visual satisfaction of people observing a water body is thus very important.

Researchers have evaluated the aesthetic quality of water bodies using clarity as a main criterion [15] [16] [20], with increased clarity positively influencing visual satisfaction [9]-[12] [16] [18] [20] [22]. Water clarity is also the main factor influencing people's perception and assessment of water quality [18] [20] [21] [23] and their recreational preferences, and promotes travel [20] [21] [23].

Water quality is one of the main factors that affect users' perceptions of the coastline environment [7] [15]; it is influenced by several parameters, including water temperature, chlorophyll content, turbidity, color, total phosphorus (TP), nitrogen, Escherichia coli (E. coli), and oil content [7] [15] [19] [22]. Given that several of these physico-chemical water parameter variables are independent, there is a need for a comprehensive water quality index that incorporates multiple measures of water quality.

Traditionally, water pollution indices have been used to determine the water quality of a water body. The development of water quality indices was initiated by Horton [24]. In 1970, the National Sanitation Foundation (NSF) [25] considered concentrations of seven water quality parameters (including DO, E. coli, BOD, ammoniac nitrogen $\left(\mathrm{NH}_{3}-\mathrm{N}\right)$, suspended solids (SS), and TP) to calculate an exponential integral value and categorize water quality into six levels, ranging from excellent to poor. The water quality index theory was subsequently applied in the development of several different water quality indices for specific applications. In Taiwan, a commonly adopted water quality assessment index is the River Pollution Index (RPI); there are also categories and quality standards pertaining to the marine environment, details of which are provided in Lee and Lee [26].

These two aforementioned water pollution assessment indices require strict thresholds for water management. However, water bodies in tourism fishing ports also need to be managed taking into account the levels of visual satisfaction of those exposed to them. It is thus very important to establish different water quality standards for tourism fishing ports, to increase the psychological comfort of tourists, and to stimulate visitation rates. There are many tourism fishing ports, with over 230 fishing ports in Taiwan, and water activities (e.g. swimming and boating) are prohibited in these areas. The visual satisfaction afforded by these water bodies is thus very important in the case of these ports, with water clarity being a critical factor [9]-[12] [15] [16] [18] [20] [22]. Indeed, water quality can also be assessed on the basis of water clarity [18] [20]. Water clarity results from a combination of various water quality parameters, and as noted, the abovementioned studies indicated that it can affect people's preferences with respect to water landscapes. Water clarity management in tourism fishing ports is very important, as water clarity can act as an intervening variable, linked both with tourists' visual satisfaction and with water quality. Meanwhile, water clarity and water quality parameters can be measured via instrumentation; we therefore take water clarity as an intervening variable to determine tourists' level of satisfaction with a water body and water quality preferences, in order to facilitate water quality management in tourism fishing ports.

Lee and Lee [26] created an integrated visual and olfactory satisfaction index through four water quality satisfaction curves, and tourists' overall satisfaction with the water body was classified into four levels; this was then used for water quality management of tourism fishing ports. It is possible to go further and develop a satisfaction model to facilitate water quality management; such a model can be based on more detailed water quality predictions. We experience scenery via a variety of sensory impressions but vision is by far our most important sense in natural settings [27]-[29] and in relation to water [30]. Given the above, our specific objectives were: 1) to identify the relationship between tourists' visual satisfaction with a water body and water clarity; 2) to identify the influence of water quality parameters on water clarity; 3 ) to use the suitability index curve method to identify correlations between water quality parameters and an individual's level of satisfaction with water clarity, 4) to consolidate mathematical equations of water clarity suitability indices by establishing curves of normalized clarity values and water quality parameters. Our results could be used to directly estimate water clarity using se- 
lected water quality parameters, while also identifying tourists' visual satisfaction with water bodies in tourism fishing ports, without the need for complicated questionnaire surveys and statistical analyses. Water clarity management for the purposes of ensuring visual satisfaction could thus be accomplished via examination of water quality parameters. The study establishes values for good water clarity and water quality that are necessary for tourist satisfaction with water bodies, to draw people to the coast and to tourism fishing ports.

\section{Materials and Methods}

\subsection{Study Area}

This study was conducted at five tourism fishing ports in Taiwan, namely FuJi, PiSha, ChuWei, YangAn, and HsinChu (Figure 1), which are very popular in Taiwan and currently host approximately 7 million tourists annually. As these five fishing ports constitute important recreational areas in the country, the quality of water in these ports is extremely important for tourism development.

FuJi fishing port has an area of approximately 2.9 ha, with a water depth of $3-4 \mathrm{~m}$, while PiSha has an area of 11.5 ha with a water depth of $4.5-8 \mathrm{~m}$. ChuWei port incorporates an area of 3.8 ha with a water depth of 2.5 - $4.5 \mathrm{~m}$, YangAn has an area of 2.8 ha with a water depth of $2.5-3 \mathrm{~m}$, and HsinChu has an area of 23.9 ha with a water depth of $3.5-5.5 \mathrm{~m}$. There is good exchange of seawater between ports and ocean because of the significant tidal range; the ports thus exhibit excellent water quality. However, there is more concentrated discharge of pollution along the wharves where fish markets and restaurants are located [31], resulting in differing water quality across these ports.

\subsection{Survey}

A survey was used to investigate water quality conditions, water clarity, and levels of tourists' visual satisfaction with water bodies in the five ports. Water quality and clarity were investigated once (in May 2007) at FuJi, YangAn, and ChuWei; the two former ports had three sampling stations, while Chuwei had four. PiSha was surveyed twice (during May and August 2007), with three sampling stations at this location, while HsinChu was surveyed six times (during March, June, September, and December of 2006, and during May and August of 2007) and had five sampling stations. Water quality and water clarity sampling were conducted simultaneously with the tourist satisfaction questionnaire surveys.

A total of 14 water quality parameters were investigated, i.e., water temperature, practical salinity, $\mathrm{DO}, \mathrm{pH}$, turbidity, conductivity, $\mathrm{NH}_{3}-\mathrm{N}$, BOD, nitratenitrogen $\left(\mathrm{NO}_{3}-\mathrm{N}\right)$, SS, chemical oxygen demand (COD), TP, fecal coliforms $(\mathrm{FC})$ and mineral oil. Water clarity and four water quality parameters (practical salinity, $\mathrm{DO}, \mathrm{pH}$, and
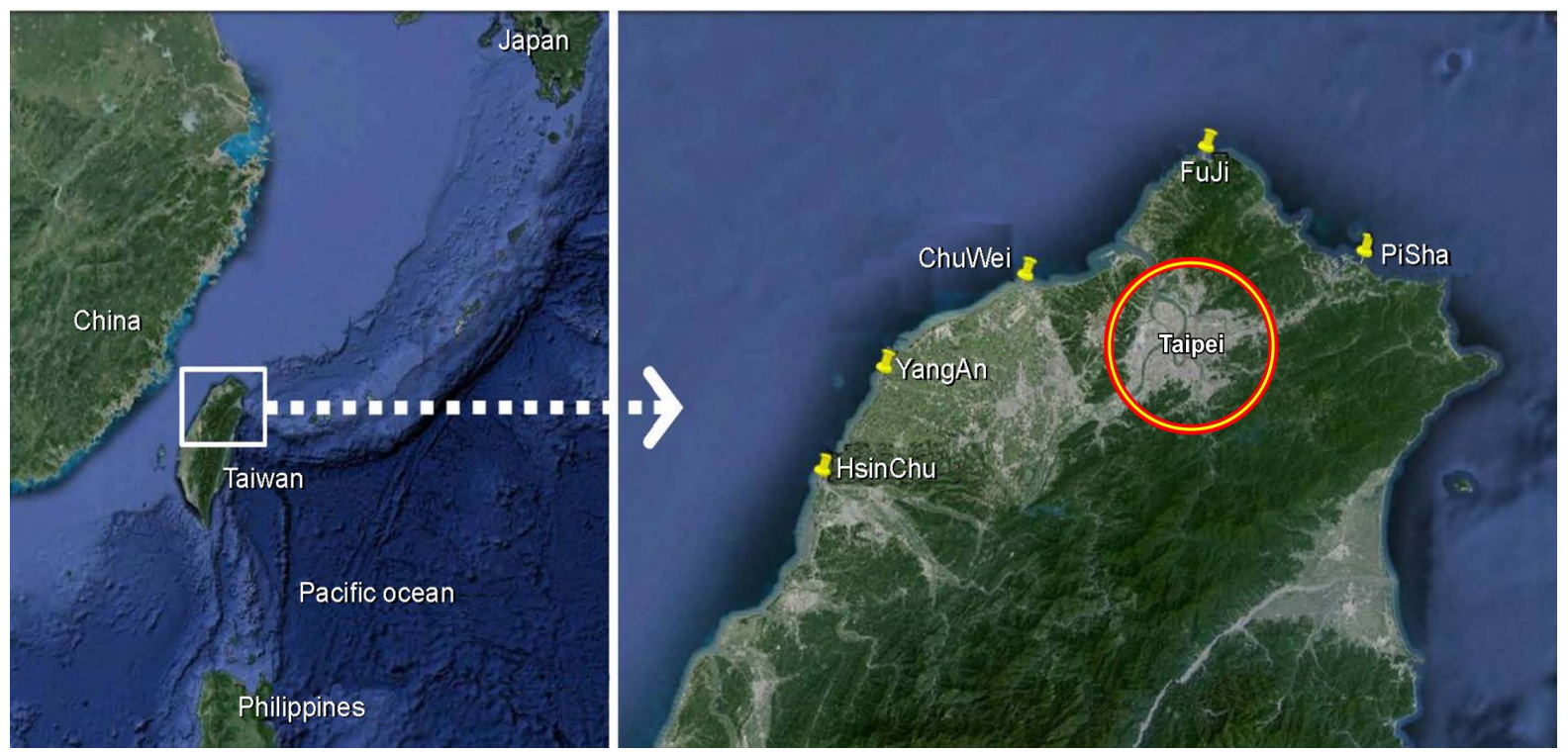

Figure 1. Location of study sites. Taipei is the provincial capital of Taiwan. 
conductivity) were assessed on site, while remaining parameters were analyzed in a laboratory. Analysis methods for clarity and all water parameters were based on standards specified by the EPA [32]. However, metal content was not included in the analysis. The Fisheries Agency [31] divides sources of water pollution in fishing ports into five types: industry, domestic/urban, aquaculture, shipping, and tourism. The main water pollution sources in these five tourist fishing ports were shipping and tourism [31], and water in these locations was therefore not expected to contain metal pollutants. Plankton and water color were also excluded, because they vary depending on other physical and chemical water quality parameters that were already being measured.

In the questionnaire survey, aside from providing demographic information, the participants were asked to report their visual satisfaction with the water body using a scale ranging from 1 (not at all satisfied) to 5 (extremely satisfied). A total of 1001 valid questionnaires were collected, with a participation rate of $8.6 \%$ at $\mathrm{FuJi}$, $8.7 \%$ at YangAn, $8.3 \%$ at ChuWei, $19.9 \%$ at PiSha, and $54.5 \%$ at HsinChu. Participants' mean level of satisfaction with the water body was not found to be related to any significant differences in gender, age, and educational level. Chen et al. [33] and Ergin et al. [9] had noted similar results. The satisfaction variable was used for reliability analysis, with the value of Cronbach's alpha being 0.898 .

\subsection{Methods}

First, we used correlation analysis to test the relationship between tourists' level of visual satisfaction and water clarity, to verify that these factors were directly related. We also used correlation analysis to test the relationship between water clarity and water quality parameters. Each water quality parameter was tested in relation to water clarity, and those parameters that were found to be significantly related were selected for further analysis.

The relationships between water clarity and water quality parameters are complex. For example, an improvement in water quality would increase the clarity of the water body; however, there are clearly some restrictions on clarity, even if water quality is optimal. Water quality management influences water clarity, with high values of the latter producing the highest levels of visual satisfaction. Given the above, we adopted the suitability index curve concept to derive research findings.

The suitability index (SI) system was originally developed by USFWS [34] and Schamberger and O'Neil [35], who noted that maximum numbers of target species were associated with optimal habitat conditions. The SI curve was drawn by plotting the number of target species and a certain habitat factor. The number of target species would be directly converted into an index of suitability, ranging from 0.0 to 1.0 for species $(0.0$ indicating unsuitable conditions and 1.0 optimal condition); this can then be applied to assess the suitability of the variable in meeting species' habitat requirements [36]. All SI curves were then integrated into a SI model used to interpret the complexities of habitat and to assess habitat quality. The SI model is mechanistic and knowledge-based, combining both research data and expert opinion [37]-[39]. We deliberately selected this SI method, which could be used to improve water clarity through water quality management, leading to higher visual satisfaction with water bodies in tourism fishing ports. The SI curve technique was chosen for this research to provide a synoptic view of water quality suitability for water clarity, as well as to assess the suitability of water quality parameters in relation to water clarity. We therefore developed SI curves for water clarity and a certain water quality parameter. Based on the concepts of USFWS [34] and Schamberger and O'Neil [35], if a specific water quality parameter is set to a certain value and if the other values of water quality parameters at the sampling station with highest water clarity are considered to be optimal, then the SI curve can be drawn via a scatter plot of water clarity and a particular water quality parameter.

We modified the SI model to create a clarity suitability index of water quality (CSIWQ). Water clarity is represented by a set of water quality parameters, with the essential characteristic of appropriate water clarity being that it enables high values for tourists' visual satisfaction. Each water quality parameter used in the clarity suitability index (CSI) curve describes the relationship between a particular water quality parameter and clarity, using values between 0 (no clarity) and 1 (very high clarity). All CSI curves are then integrated to create the CSIWQ model. Mathematical and logical relationships used to calculate CSIWQ scores varied, depending upon the number and types of CSI variables included in the model; the relationships between water quality variables are complex, with these needing to be integrated and combined with water clarity. If water quality is good, with high concentrations of DO, the concentrations of BOD, TP, and SS are lower. Water clarity correlates with a set of water quality parameters; meanwhile water quality parameters are also associated with each other. Based on the SI model and on water pollution indices, influences on water quality and water clarity effects were not 
closely related in regression analysis. As a result, we used continued product (CP), arithmetic mean (AM), or geometric mean (GM) (i.e., $\left[x_{1} \times x_{2} \times \cdots \times x_{n}\right],\left[x_{1}+x_{2}+\cdots+x_{n}\right] n$, and $\left[x_{1} \times x_{2} \times \cdots \times x_{n}\right]^{1 / n}$, respectively) [34] [40] [41] to combine variables representing water clarity requisites, or tangible resources.

It is known that water quality affects water clarity, and that clarity then influences a tourist's visual satisfaction values. The CSIWQ model can be employed to calculate water clarity in relation to water quality, and it is potentially possible to also consider effective and easier water quality management strategies using this method.

\section{Results}

\subsection{Correlations between Visual Satisfaction and Water Clarity, and Between Water Clarity and Water Quality Parameters}

The mean ratings for satisfaction with the water body were $1.87(\mathrm{SD}=0.27), 3.23(\mathrm{SD}=0.49), 2.53(\mathrm{SD}=0.24)$, $1.99(\mathrm{SD}=0.12)$, and $3.50(\mathrm{SD}=0.83)$ at FuJi, YangAn, ChuWei, PiSha, and HsinChu, respectively. The corresponding water clarity results for the same sites were $0.47 \mathrm{~m}, 1.25 \mathrm{~m}, 0.59 \mathrm{~m}, 0.48 \mathrm{~m}$, and $1.53 \mathrm{~m}$.

The CSIWQ model was based on the relationship between water clarity and water quality parameters and was used for deriving tourists' level of satisfaction with water bodies. For this reason, correlation analysis was used to explain the nature and extent of the relationship between tourists' visual satisfaction and water clarity. Results showed that water clarity was significantly related to tourists' feeling of satisfaction, with the correlation coefficient indicating a strong positive relationship between the average mean score for visual satisfaction and water clarity $(\mathrm{R}=0.861, \mathrm{p}=0.000)$. We used linear regression to test the power of water clarity to predict visual satisfaction, with this predictive power found to be $74.2 \%\left(\mathrm{R}^{2}\right.$ (adjusted for d.f.) $=0.736$ ).

We then tested the correlation between water clarity and 14 water parameters. Results showed that water clarity was significantly correlated with six water quality parameters, namely $\mathrm{DO}(\mathrm{R}=0.768, \mathrm{p} \leq 0.01), \mathrm{NH}_{3}-\mathrm{N}(\mathrm{R}=$ $-0.708, \mathrm{p} \leq 0.01)$, $\mathrm{BOD}(\mathrm{R}=-0.618, \mathrm{p} \leq 0.01)$, TP $(\mathrm{R}=-0.712, \mathrm{p} \leq 0.01), \mathrm{NO}_{3}-\mathrm{N}(\mathrm{R}=-0.313, \mathrm{p} \leq 0.05)$, and $\mathrm{SS}(\mathrm{R}=-0.679, \mathrm{p} \leq 0.01)$. These six water quality parameters were therefore inferred to significantly influence water clarity. The remaining eight parameters (changes in water temperature, practical salinity, $\mathrm{pH}$, turbidity, conductivity, COD, FC, and mineral oil) were not significantly correlated with changes in water clarity, with these parameters thus given minimal importance in subsequent analysis.

\subsection{CSI of Water Clarity and Water Quality Parameters}

When establishing a CSI curve, the properties and importance of various water quality parameters should first be determined. These can then be used as the basis for selecting appropriate and representative parameters. Correlation analysis results showed that $\mathrm{DO}, \mathrm{NH}_{3}-\mathrm{N}, \mathrm{BOD}, \mathrm{TP}, \mathrm{NO}_{3}-\mathrm{N}$, and $\mathrm{SS}$ trends correlated with water clarity; we thus estimated collinearity in regression analysis before establishing the CSI curve. According to VIF-value results, $\mathrm{NH}_{3}-\mathrm{N}$ and $\mathrm{NO}_{3}-\mathrm{N}$ occurred in a co-linear manner and were thus eliminated; DO, BOD, TP, and SS were retained to further refine the CSI curve. Based on the SI concept, we utilized the normalized water clarity value on the vertical axis and the values of individual water parameters on the horizontal axis; we then established an envelope based on the scatter plots of normalized water clarity and of a particular water parameter, (i.e., CSI for clarity and DO, BOD, TP, and SS, as shown in Figures 2-5).

A specific CSI curve is derived from the scatter-plot for clarity and a certain water quality parameter, assuming that other water quality parameters are fixed. For example, with reference to the CSI shown in Figure 2, a tourism fishing port with highest water clarity, in which DO must be over $9.0 \mathrm{mg} / \mathrm{L}$, reflects the situation when other parameters (such as BOD, TP, and SS) are also at their optimal values. However, water clarity is not based only on DO; if DO is fixed, water clarity may be affected by other water quality parameters. In other words, if another tourism fishing port exhibits a DO level of $9.0 \mathrm{mg} / \mathrm{L}$, but its water clarity level is lower, that would be due to the effect of other water quality parameters.

\subsection{CSIWQ Model Selection and Validation}

The CSIWQ model was produced from the formulae of all CSIs, applied to manage water quality to achieve high levels of visual satisfaction with water bodies in tourism fishing ports. We began by formulating a two-stage process and then established the CSIWQ model. First, we applied a general linear model (GLM) procedure to test for water clarity-dependent variables and the interaction effect of independent variables (DO, BOD, TP, 
and SS). The interaction effect of TP and SS was significant $(F=2.340, p=0.035)$ and was weighted accordingly in the CSIWQ model test; other interaction effects for other parameters were not significant.

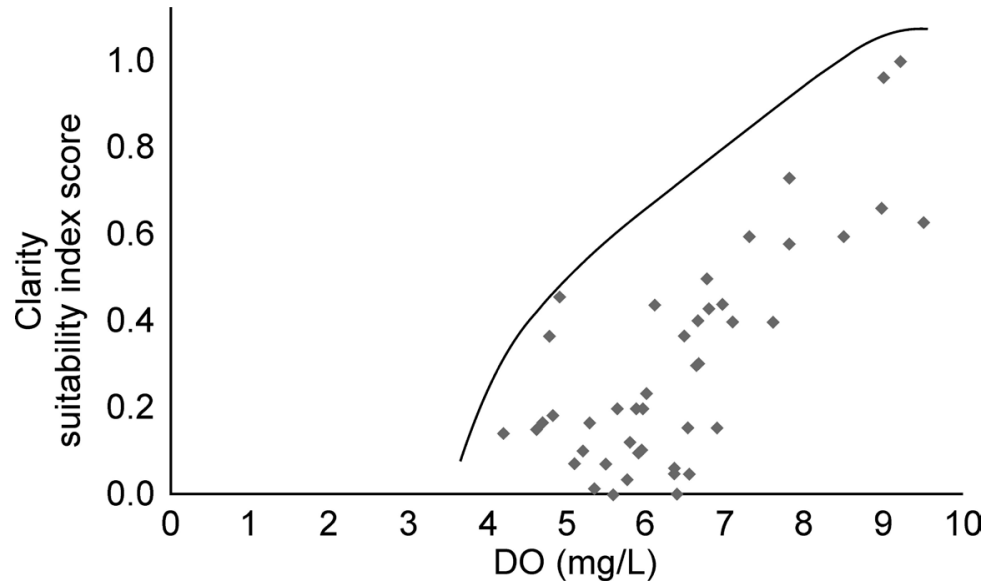

Figure 2. Clarity suitability index (CSI) curve for normalized values of water clarity and DO. The maximum value of the CSI can be obtained at DO concentrations greater than $9.0 \mathrm{mg} / \mathrm{L}$.

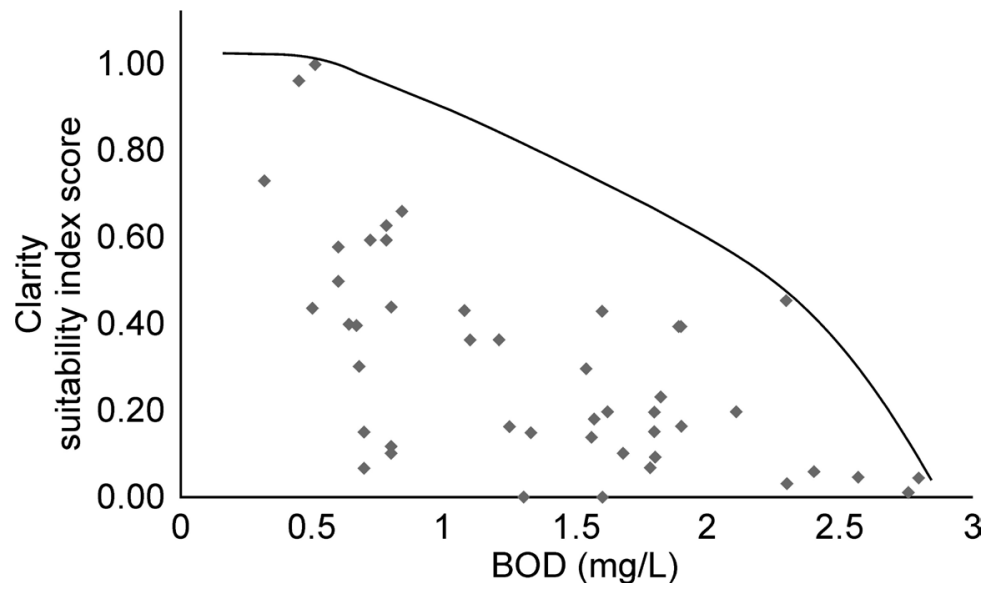

Figure 3. Clarity suitability index (CSI) curve for normalized values of water clarity and BOD. The maximum value of the CSI can be obtained at BOD concentrations less than $0.5 \mathrm{mg} / \mathrm{L}$.

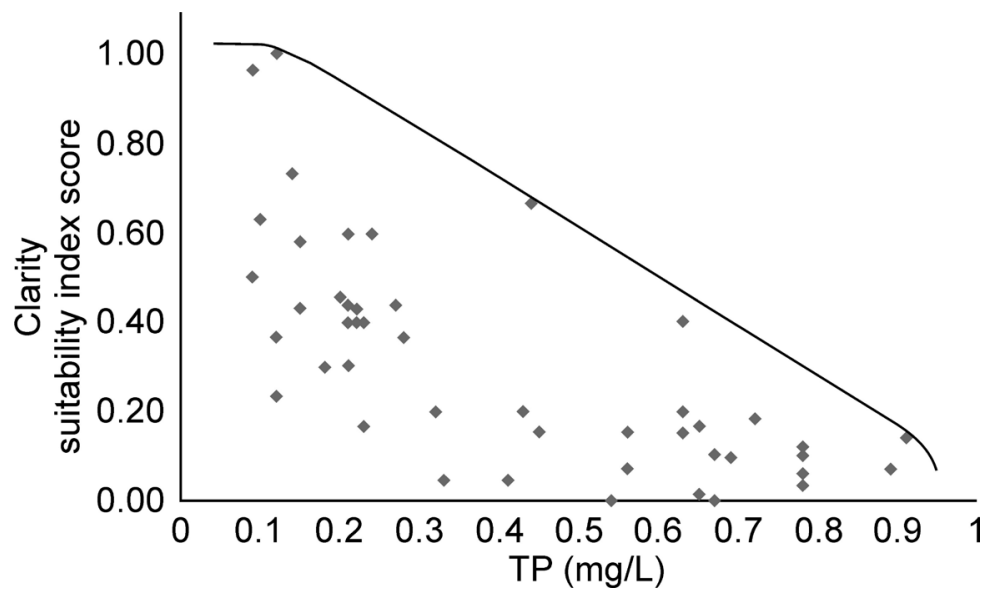

Figure 4. Clarity suitability index (CSI) curve for normalized values of water clarity and TP. The maximum value of the CSI could be obtained at TP concentrations less than $0.12 \mathrm{mg} / \mathrm{L}$. 


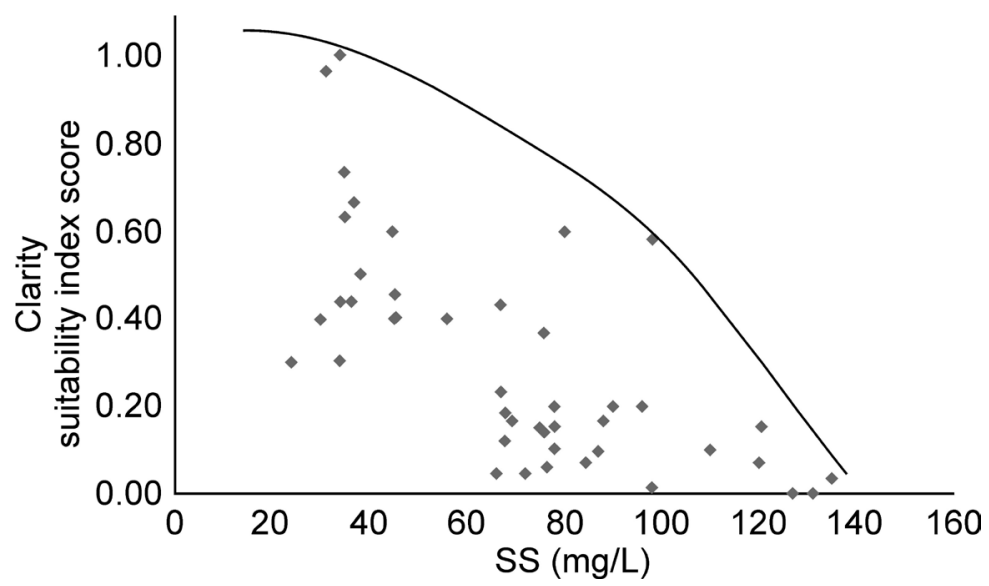

Figure 5. Clarity suitability index (CSI) curve for normalized values of water clarity and SS. The maximum value of the CSI could be obtained at SS concentrations less than $45.0 \mathrm{mg} / \mathrm{L}$.

The estimated values of the CSIWQ model using CP, AM, and GM, were therefore verified with field data for water clarity values, and goodness of fit was evaluated. The $\mathrm{CP}$ approach was found to provide the best fit and was most appropriate for indicating water quality in tourism fishing ports, as shown in Equation (1) below:

$$
\mathrm{CSIWQ}=\mathrm{CSI}_{\mathrm{DO}} \times \mathrm{CSI}_{\mathrm{BOD}} \times\left(\mathrm{CSI}_{\mathrm{TP}} \times \mathrm{CSI}_{\mathrm{SS}}\right)^{1.5}
$$

\section{Discussion and Conclusions}

The present study indicated that tourists' visual satisfaction with water bodies in tourism fishing ports was influenced by water clarity, and that this influence was positive and strong; similar findings have been noted in the literature [9]-[12] [16] [18] [20] [22]. Improving water clarity led to an increase in visual satisfaction; in many situations, aesthetic reactions suggest that water clarity is a primary concern for people [18]. Water clarity is influenced by water quality, and changes in water quality are in turn reflected in water clarity; these factors should therefore be considered in assessing tourists' visual satisfaction and their rating score [7] [13] [15] [19] [20].

Four of the 14 water quality parameters considered had discernible effects on water clarity; the influence of these four parameters was independent, with no collinearity. DO had a positive influence, and BOD, TP, and SS had a negative influence. These four parameters were used with normalized water clarity values for establishing CSI curves, which were integrated into the CSIWQ model using the CP approach. The CSIWQ model was the most suitable model for predicting suitable water clarity when using the four CSI curves for DO, BOD, TP, and SS, with these results almost identical to the findings of Lee and Lee [26]. The latter authors showed that DO, clarity, BOD, and TP affected tourists' visual satisfaction with a water body; SS was negligible because the relationship between SS and clarity was collinear. Both research studies developed differential functions for water quality management based on tourists' satisfaction with a water body in tourism fishing ports.

This result mainly illustrates the ease of obtaining a reliable prediction of water clarity and tourists' visual satisfaction by estimating CSIWQ values and using field data for only DO, BOD, TP, and SS. As shown in Table 1, a CSIWQ value lower than 0.4 indicates that real water clarity will be less than $1.52 \mathrm{~m}$ and that tourists' visu-

Table 1. Visual satisfaction with water body and water clarity in tourism fishing ports (Taiwan), based on CSIWQ using continued product (CP) approach.

\begin{tabular}{ccc}
\hline CSIWQ value & Clarity $(\mathrm{m})$ & Visual satisfaction value $^{*}$ \\
\hline score $>0.8$ & $>2.64$ & $>4.4$ \\
$0.6-0.8$ & $2.08-2.64$ & $3.9-4.4$ \\
$0.4-0.6$ & $1.52-2.08$ & $3.2-3.9$ \\
$0.2-0.4$ & $0.95-1.52$ & $2.7-3.2$ \\
score $<0.2$ & $<0.95$ & $<2.7$
\end{tabular}

*level of visual satisfaction with water body: 1 -not at all satisfied, 2 - slightly satisfied, 3 -moderately satisfied, 4 - very satisfied, 5 - extremely satisfied. 
al satisfaction would decrease below the level of moderate satisfaction. When the CSIWQ value is higher than 0.6 and real water clarity is more than $2.08 \mathrm{~m}$, tourist perceptions would reflect high levels of satisfaction. When trying to increase tourist numbers in tourism fishing ports, the improvement of water clarity is essential. Vesterinen et al. [20] asserted that an increase in the number of tourists was accompanied by an increase in water clarity. Our research findings showed that when water clarity increased by $0.5 \mathrm{~m}$, tourists' level of satisfaction increased by a value of one.

Further, CSI curves of DO, BOD, TP, and SS are a significant and somewhat creative method for water quality management in tourism fishing ports. As noted, tourists' visual satisfaction with a water body is influenced by water clarity; in turn, and as reflected in many studies, DO, BOD, TP, and SS influence water clarity. DO is an important parameter for assessing water quality, while BOD is widely used as an indicator of the organic quality of water (i.e., the degree of organic pollution of water) [42] [43]. Moreover, oxygen affects water indicators, not only biochemical ones, but also aesthetic ones such as water clarity; excess BOD can lead to a decrease in water clarity. The addition of even a small amount of phosphorus to a water body has a negative effect on water quality, leading to phenomena such as algal blooms. Meanwhile increasing algae will reduce water clarity, thus causing a shortage of oxygen in water. SS can lead to physical alterations in the water body, such as reduced penetration of light; these physical alterations are associated with undesirable aesthetic effects [44]. The CSI curve indicates the major optimal values of DO, BOD, TP, and SS for water clarity; these parameters are also important for ensuring high levels of visual satisfaction.

CSI curves showed that if the concentration of DO in water increases to $9.0 \mathrm{mg} / \mathrm{L}$, and if BOD, TP, and SS are lower than $0.5 \mathrm{mg} / \mathrm{L}, 0.12 \mathrm{mg} / \mathrm{L}$, and $45.0 \mathrm{mg} / \mathrm{L}$, respectively, water clarity would be optimal, producing the highest levels of visual satisfaction among tourists. The findings of the CSI curve will not only help to indicate effective water quality management but are also essential to support land-use control for long-term development of tourism fishing ports. We have extensively considered the prohibition on water access and activities in these locations and concluded that the higher visual preference values for water bodies are thus very important. Compared to existing water pollution indices, the CSIWQ model can not only achieve the objective of assessing preferences, but is also able to do this more easily and cost-effectively.

The results of our research have some limitations, which should be noted. The main water pollution sources considered for these five tourism fishing ports were tourism and ship emissions [31]; oil pollution was not considered as significant due to the large tidal range. Nevertheless, the WHO [45] showed that oil can form a film on the water's surface and that even a very small quantity of oil can make water aesthetically unattractive. Long-term monitoring may therefore need to incorporate additional water quality parameters, in line with an increase in the number of tourists or with the emergence of new pollution sources; these may include industry wastewater, domestic pollution, urban pollution, or aquaculture water pollution.

To date, tourists' satisfaction with water bodies in tourism fishing ports, based on their integrated perception via manifold senses, has been ignored. However, port and coastal tourism is increasing. A model integrating multisensory satisfaction, such as integrated visual and olfactory perceptions, is thus also worth discussing.

Furthermore, understanding the microbiological and physicochemical processes occurring among different constituents of water quality could help to explain the relevance and dependence/independence of public aesthetic preferences, water clarity, and certain water quality parameters. We also recommend that this innovative CSIWQ technique be developed as a water quality management tool for planners of fishing ports, reflecting tourists' visual satisfaction based on the clarity and quality of water.

\section{References}

[1] Bulut, Z. and Yilmaz, H. (2009) Determination of Waterscape Beauties through Visual Quality Assessment Method. Environmental Monitoring and Assessment, 154, 459-468. http://dx.doi.org/10.1007/s10661-008-0412-5

[2] Herzog, T.R. (1985) A Cognitive Analysis of Preference for Waterscapes. Journal of Environmental Psychology, 5, 225-241. http://dx.doi.org/10.1016/S0272-4944(85)80024-4

[3] Faggi, A., Breuste, J., Madanes, N., Gropper, C. and Perelman, P. (2013) Water as an Appreciated Feature in the Landscape: A Comparison of Residents' and Visitors' Preferences in Buenos Aires. Journal of Cleaner Production, 60, 182-187. http://dx.doi.org/10.1016/i.jclepro.2011.09.009

[4] Howley, P. (2011) Landscape Aesthetics: Assessing the General Publics' Preferences towards Rural Landscapes. Ecological Economics, 72, 161-169. http://dx.doi.org/10.1016/j.ecolecon.2011.09.026

[5] Wherrett, J.R. (2000) Creating Landscape Preference Models Using Internet Survey Techniques. Landscape Research, 
25, 79-96. http://dx.doi.org/10.1080/014263900113181

[6] White, M., Smith, A., Humphryes, K., Pahl, S., Snelling, D. and Depledge, M. (2010) Blue Space: The Importance of Water for Preference, Affect, and Restorativeness Ratings of Natural and Built Scenes. Journal of Environmental Psychology, 30, 482-493. http://dx.doi.org/10.1016/j.jenvp.2010.04.004

[7] Cervantes, O. and Espejel, I. (2008) Design of an Integrated Evaluation Index for Recreational Beaches. Ocean and Coastal Management, 51, 410-419. http://dx.doi.org/10.1016/j.ocecoaman.2008.01.007

[8] Chokor, B.A. and Mene, S.A. (1992) An Assessment of Preference for Landscapes in the Developing World: Case Study of Warri, Nigeria, and Environs. Journal of Environment Management, 34, 237-256. http://dx.doi.org/10.1016/s0301-4797(11)80001-0

[9] Ergin, A., Karaesmen, E., Micallef, A. and Williams, A. (2004) A New Methodology for Evaluating Coastal Scenery: Fuzzy Logic Systems. Area, 36, 367-386. http://dx.doi.org/10.1111/j.0004-0894.2004.00238.x

[10] Ergin, A., Özölçer, İ.H. and Şahin, F. (2010) Evaluating Coastal Scenery Using Fuzzy Logic: Application at Selected Sites in Western Black Sea Coastal Region of Turkey. Ocean Engineering, 37, 583-591. http://dx.doi.org/10.1016/j.oceaneng.2010.02.003

[11] Ergin, A., Karaesmen, E. and Uçar, B. (2011) A Quantitative Study for Evaluation of Coastal Scenery. Journal of Coastal Research, 27, 1065-1075. http://dx.doi.org/10.2112/JCOASTRES-D-09-00093.1

[12] Ergin, A., Williams, A. and Micallef, A. (2006) Coastal Scenery: Appreciation and Evaluation. Journal of Coastal Research, 22, 958-964. http://dx.doi.org/10.2112/04-0351.1

[13] Khattabi, A., Williams, T. and Ergin, A. (2011) Assessment of Quality and Attraction of the Sandy Beaches of Nador Province-Morocco. In: Bayed, A., Ed., Sandy Beaches and Coastal Zone Management-Proceedings of the 5th International Symposium on Sandy Beaches, Rabat, 19-23 October 2009, 59-64.

[14] Lothian, A. (2005) Coastal Viewscapes of South Australia. Report for the Coast Protection Branch, South Australian Department for Environment and Heritage.

[15] Morgan, R. (1999) A Novel, User-Based Rating System for Tourist Beaches. Tourism Management, 20, $393-410$. http://dx.doi.org/10.1016/S0261-5177(99)00015-1

[16] Smith, D.G., Croker, G.F. and Mcfarlane, K. (1995) Human Perception of Water Appearance. New Zealand Journal of Marine and Freshwater Research, 29, 29-43. http://dx.doi.org/10.1080/00288330.1995.9516637

[17] Uchida, T. (1995) The Amenity Value Evaluation to the Urban Coastal Environment. Proceedings of the Japan Society of Civil Engineers, 509, 211-220.

[18] Ryan, P.A. (1991) Environmental Effects of Sediment on New Zealand Streams: A Review. New Zealand Journal of Marine and Freshwater Research, 25, 207-221. http://dx.doi.org/10.1080/00288330.1991.9516472

[19] Pfluger, Y., Rackham, A. and Larned, S. (2010) The Aesthetic Value of River Flows: An Assessment of Flow Preferences for Large and Small Rivers. Landscape and Urban Planning, 95, 68-78. http://dx.doi.org/10.1016/j.landurbplan.2009.12.004

[20] Vesterinen, J., Pouta, E., Huhtala, A. and Neuvonen, M. (2010) Impacts of Changes in Water Quality on Recreation Behavior and Benefits in Finland. Journal of Environmental Management, 91, 984-994. http://dx.doi.org/10.1016/j.jenvman.2009.12.005

[21] Anfuso, G., Williams, A.T., Cabrera Hernández, J.A. and Pranzini, E. (2014) Coastal Scenic Assessment and Tourism Management in Western Cuba. Tourism Management, 42, 307-320. http://dx.doi.org/10.1016/j.tourman.2013.12.001

[22] Somerville, S.E., Miller, K.J. and Mair, J.M. (2003) Assessment of the Aesthetic Quality of a Selection of Beaches in the Firth of Forth, Scotland. Marine Pollution Bulletin, 46, 1184-1190. http://dx.doi.org/10.1016/S0025-326X(03)00126-7

[23] Kirillova, K., Fu, X., Lehto, X. and Cai, L. (2014) What Makes a Destination Beautiful? Dimensions of Tourist Aesthetic Judgment. Tourism Management, 42, 282-293. http://dx.doi.org/10.1016/j.tourman.2013.12.006

[24] Horton, R.K. (1965) An Index Number System for Rating Water Quality. Journal of the Water Pollution Control Federation, 37, 300-306.

[25] Brown, R.M., McLelland, N.I., Deininger, R.A. and Tozer, R.G. (1970) A Water Quality Index: Do We Dare? Water Sewage Works, 117, 339-343.

[26] Lee, L.H. and Lee, Y.D. (2015) The Impact of Water Quality on the Visual and Olfactory Satisfaction of Tourists. Ocean and Coastal Management, 105, 92-99. http://dx.doi.org/10.1016/j.ocecoaman.2014.12.020

[27] Kaplan, S. (1992) Perception and Landscape: Conceptions and Misconceptions. In: Nasar, J., Ed., Environmental Aesthetics: Theory, Research, and Application, Cambridge University Press, Cambridge, 45-55.

[28] Van den Berg, A.E., De Vries, D. and Vlek, C.A.J. (2006) Images of Nature, Environmental Values, and Landscape Preference: Exploring Their Relationships. In: Van den Born, R.J.G., Lenders, R.H.J. and De Groot, W.T., Eds., Vi- 
sions of Nature: A Scientific Exploration of People's Implicit Philosophies Regarding Nature in Germany, the Netherlands and the United Kingdom, LIT-Verlag, Münster, 41-60. http://agnesvandenberg.nl/images.pdf

[29] Velarde, M.D., Fry, G. and Tveit, M. (2007) Health Effects of Viewing Landscapes: Landscape Types in Environmental Psychology. Urban Forestry and Urban Greening, 6, 199-212. http://dx.doi.org/10.1016/j.ufug.2007.07.001

[30] Yamashita, S. (2002) Perception and Evaluation of Water in Landscape: Use of Photo-Projective Method to Compare Child and Adult Residents' Perceptions of a Japanese River Environment. Landscape and Urban Planning, 62, 3-17. http://dx.doi.org/10.1016/S0169-2046(02)00093-2

[31] Fisheries Agency (2006) A Study on the Integrated Strategies of Marine Pollution Control in the Fishing Ports. Council of Agriculture Executive Yuan, R.O.C.

[32] Environmental Protection Administration, ROC (EPA) (2014) Environmental Water Quality Monitoring and Information Management. http://wq.epa.gov.tw/Code/Business/ItemMethod.aspx

[33] Chen, B., Adimo, O.A. and Bao, Z. (2009) Assessment of Aesthetic Quality and Multiple Functions of Urban Green Space from the Users' Perspective: The Case of Hangzhou Flower Garden, China. Landscape and Urban Planning, 93, 76-82. http://dx.doi.org/10.1016/j.landurbplan.2009.06.001 Steinwender, A., Gundacker, C. and Wittmann, K.J. (2008) Objective versus Subjective Assessments of Environmental Quality of Standing and Running Waters in a Large City. Landscape and Urban Planning, 84, 116-126. http://dx.doi.org/10.1016/j.landurbplan.2007.07.001

[34] US Fish and Wildlife Service (USFWS) (1981) Standards for the Development of Habitat Suitability Index Models. US Fish and Wildlife Service, Division of Ecological Service, Washington DC.

[35] Schamberger, M.L. and O’Neil, L.J. (1986) Concepts and Constraints of Habitat-Model Testing. In: Vemer, J., Momson, M.L. and Ralph, C.J., Eds., Wildlife 2000, the University of Wisconsin Press, Madison, 177-182.

[36] US Fish and Wildlife Service (USFWS) (1986) Habitat Suitability Index Models and Instream Flow Suitability Curves. US Fish and Wildlife Service, Division of Ecological Service, Washington DC.

[37] Amici, V., Geri, F. and Battistic, C. (2010) An Integrated Method to Create Habitat Suitability Models for Fragmented Landscapes. Journal for Nature Conservation, 18, 215-223. http://dx.doi.org/10.1016/j.jnc.2009.10.002

[38] Wang, F. and Lin, B. (2013) Modelling Habitat Suitability for Fish in the Fluvial and Lacustrine Regions of a New Eco-City. Ecological Modelling, 267, 115-126. http://dx.doi.org/10.1016/j.ecolmodel.2013.07.024

[39] Zohmann, M., Pennerstorfer, J. and Nopp-Mayr, U. (2013) Modelling Habitat Suitability for Alpine Rock Ptarmigan (Lagopus muta helvetica) Combining Object-Based Classification of IKONOS Imagery and Habitat Suitability Index Modelling. Ecological Modelling, 254, 22-32. http://dx.doi.org/10.1016/j.ecolmodel.2013.01.008

[40] Grebenkov, A., Lukashevich, A., Linkov, I. and Kapustka, L. (2006) A Habitat Suitability Evaluation Technique and Its Application to Environmental Risk Assessment. Detection and Disposal of Improvised Explosives. Springer, Dordrecht, 191-201.

[41] US Fish and Wildlife Service (USFWS) (1986) Habitat Suitability Index Model: Inland Silverside. US Fish and Wildlife Service, Division of Ecological Service, Washington DC.

[42] US Environmental Protection Agency (US EPA) (2015) Dissolved Oxygen and Biochemical Oxygen Demand. http://water.epa.gov/type/rsl/monitoring/vms52.cfm

[43] US Environmental Protection Agency (US EPA) (2015) Total Phosphorus. http://www.epa.gov/region9/water/tribal/training/pdf/TotalPhosphorus.pdf

[44] Bilotta, G.S. and Brazier, R.E. (2008) Understanding the Influence of Suspended Solids on Water Quality and Aquatic Biota. Water Research, 42, 2849-2861. http://dx.doi.org/10.1016/j.watres.2008.03.018

[45] World Health Organization (WHO) (2003) Guidelines for Safe Recreational Water Environments. Volume 1: Coastal and Fresh Waters. World Health Organization, Geneva. 


\section{Submit or recommend next manuscript to SCIRP and we will provide best service for you:}

Accepting pre-submission inquiries through Email, Facebook, Linkedin, Twitter, etc A wide selection of journals (inclusive of 9 subjects, more than 200 journals)

Providing a 24-hour high-quality service

User-friendly online submission system

Fair and swift peer-review system

Efficient typesetting and proofreading procedure

Display of the result of downloads and visits, as well as the number of cited articles

Maximum dissemination of your research work

Submit your manuscript at: http://papersubmission.scirp.org/ 